\title{
On the feedback of the winter NAO-driven sea ice anomalies
}

\author{
Javier García-Serrano *, Claude Frankignoul \\ LOCEAN/IPSL, Sorbonne Universités (UPMC, Université Paris 06)-CNRS-IRD-MNHN, Paris, France
}

Revised for Climate Dynamics: September $3^{\text {rd }} 2015$

* Currently at: Earth Sciences Dept., Barcelona Supercomputing Center (BSC-CNS), Barcelona, Spain javier.garcia@bsc.es 


\section{On the feedback of the winter NAO-driven sea ice anomalies}

\author{
J. García-Serrano ${ }^{1,2}$, C. Frankignoul ${ }^{1}$
}

${ }^{1}$ LOCEAN/IPSL, Sorbonne Universités (UPMC)-CNRS-IRD-MNHN, Paris, France

${ }^{2}$ Earth Sciences Department, Barcelona Supercomputing Center (BSC-CNS), Barcelona, Spain

\section{Abstract}

Satellite-derived sea-ice concentration (SIC) and re-analysed atmospheric data are used to analyse the potential feedback of the North Atlantic Oscillation (NAO)-driven sea-ice anomalies in winter onto the atmosphere during 1979-2013. A maximum covariance analysis shows that this feedback can be detected with monthly data. When SIC leads, the covariability between Atlantic SIC and the Euro-Atlantic atmospheric circulation in February is statistically significant, but shows intra-seasonal differences: the December SIC influence is dominated by anomalies east of Greenland, with maximum amplitude in the Greenland Sea (GS); while the January SIC influence is dominated by anomalies west of Greenland, in the Davis Strait-Labrador Sea (DL) region. The lagged atmospheric anomalies are likewise different. A reduction of SIC over GS in December is followed in February by a negative NAO-like pattern near the surface and a hemispheric signature in the upper-troposphere, thus acting as a negative feedback. On the other hand, a reduction of SIC over DL in January is followed by an atmospheric anomaly over the North Atlantic that projects on the positive phase of the East Atlantic pattern. The dynamics associated with these atmospheric anomalies is described, indicating that transient-eddy activity is likely at work in settling the large-scale patterns. The role of concomitant North Atlantic sea surface temperature anomalies is discussed. 


\section{Introduction}

The winter North Atlantic Oscillation (NAO) dominates the interannual atmospheric variability in the Euro-Atlantic sector and largely contributes to regional climate variability (e.g. Hurrell et al. 2003; Hurrell and Deser 2009). The winter NAO also drives substantial variability in sea-ice concentration (SIC; e.g. Fang and Wallace 1994; Deser et al. 2000) and sea-surface temperature (SST; e.g. Cayan 1992; Visbeck et al. 2003) via surface wind and heat flux changes. These NAO-induced SIC and SST fluctuations may feedback onto the atmosphere and could thus contribute to climate predictability because of their persistence (e.g. Walsh and Johnson 1979; Frankignoul 1985). The aim of this study is to analyse the observed feedback of the winter NAOdriven sea-ice anomalies and explore its intra-seasonal behaviour.

Previous studies have shown that the winter NAO impact on Atlantic SIC consists of a dipole between the east and west of Greenland, with a positive NAO leading to sea-ice reduction over the Greenland-Barents Seas and sea-ice increase in the Davis StraitLabrador Sea region, and conversely for a negative NAO (Fang and Wallace 1994; Deser et al. 2000; Wu and Zhang 2010; Frankignoul et al. 2014). Atmospheric general circulation model (AGCM) experiments have been used to investigate the response to this NAO-driven SIC dipole, showing that the equilibrium circulation anomaly projects on the NAO pattern (Alexander et al. 2004; Deser et al. 2004; Magnusdottir et al. 2004) and is reached in about two months (Deser et al. 2007). They highlighted the strong

51 SIC-induced surface heat fluxes and the important role of transient-eddies in changing the initial, baroclinic response into the equivalent barotropic NAO-like response. Their 
53 results pointed out that this feedback onto the atmosphere is negative: i.e. the NAO

54 polarity of the response is opposite to the one forcing the sea-ice anomalies.

56 Two studies have established this sea-ice negative feedback from the observations, in 57 agreement with the AGCM results (Strong et al. 2009; Frankignoul et al. 2014). By 58 prescribing the dipolar SIC anomaly and the NAO patterns in an extended winter season 59 (December-to-April), Strong et al. (2009) showed that the feedback operates due to the 60 persistence of the dipole-like SIC anomaly (longer than two months). Frankignoul et al. 61 (2014) tackled the problem by making no a-priori assumption on the spatial patterns, 62 and obtained a significant NAO-like circulation anomaly lagging the SIC dipole by 6-8 63 weeks; however, they used the same extended winter season as in Strong et al. (2009), 64 which prevents from isolating the key SIC month for atmospheric predictability. In this study, we refine their analysis and consider separate monthly anomalies in both SIC and

66 the atmosphere, thus focusing on the intra-seasonal time-scale. We find that SIC 67 anomalies east and west of Greenland are associated in different months with distinct 68 circulation anomalies in the Euro-Atlantic sector. We also analyse the dynamics 69 involved in the atmospheric circulation lagging the NAO-driven sea-ice changes.

\section{Method and datasets}

The potential influence of winter SIC anomalies onto the atmosphere is first identified by a lag maximum covariance analysis (MCA; e.g. Bretherton et al. 1992; Czaja and

75 Frankignoul 2002) between monthly North Atlantic SIC and sea level pressure (SLP) anomalies. MCA performs a singular value decomposition of the (area-weighted) covariance matrix between two fields, and provides a pair of spatial patterns and 
associated standardized time-series (hereafter, expansion coefficients) for each covariability mode, which is characterized by its squared covariance (SC), the squared covariance fraction $(\mathrm{SCF})$, and the correlation between expansion coefficients (COR). The statistical significance of the MCA modes is evaluated with a Monte-Carlo test, based on 100 permutations shuffling only the atmospheric field (SLP) with replacement; the significance level is given by the numbers of randomized values that exceed the actual values being tested. As MCA maximizes the covariance, the primary test for statistical significance is the one upon SC (e.g. Gan and Wu 2015); SCF and COR usually yield lower significance levels (see Table 1). Area-averaged SIC indices are also defined to analyse atmospheric anomalies lagging sea-ice changes. For ease of comparison with previous studies, all SIC and MCA-SIC time-series are referred to seaice reduction over the target region.

90

This study uses SIC data from the NOAA/NCDC passive microwave monthly Northern Hemisphere sea-ice concentration record for 1979-2013, provided by the National Snow and Ice Data Center (NSIDC; Comiso 2012). No threshold for absence/presence of sea-

94 ice has been applied, i.e. continuous fractions have been considered. SST data from the NOAA extended reconstructed SST v3b (Smith et al. 2008) is also used. All atmospheric fields are given by the ERA-Interim re-analysis (ERA-int), available at the

97 European Centre for Medium-range Weather Forecasts (ECMWF; Dee et al. 2011). In addition to SLP, monthly geopotential height at 200hPa (Z200; as representative of the upper-troposphere) and 50hPa (Z050; as representative of the lower-stratosphere) have

100 been retrieved. Daily fields are used to analyse the role of internal dynamics: the transient-eddy momentum flux ( $u^{\prime} v^{\prime}$ ) at $200 \mathrm{hPa}$ is considered to assess the interaction

102 between eddies and mean-flow through barotropic processes (e.g. Hoskins et al. 1983; 
103 Trenberth 1986); and, the transient-eddy heat flux (v'T') at $850 \mathrm{hPa}$ is considered to

104 evaluate the impact of baroclinic processes and changes in low-level waves (e.g.

105 Andrews et al. 1987; Wallace et al. 1988). The monthly-mean covariances have been

106 computed from filtered daily data using the $24 \mathrm{~h}$-difference filter (e.g. Wallace et al.

107 1988; Chang and $\mathrm{Fu}$ 2002). To assess the anomalous heating of the lower troposphere

108 through changes in the surface turbulent heat flux, 3-hourly forecast-accumulated

109 sensible and latent heat flux initialized twice a day (00h, 12h) are also employed. All

110 monthly anomalies are calculated by subtracting the corresponding monthly

111 climatology. To reduce the effect of long-term nonlinear trends, a least squares fit at

112 each grid-point is used to remove a third-order polynomial (i.e. cubic trend) from all

113 data. It was verified that the results were not sensitive to this particular criteria.

\section{Results}

\subsection{Identification of the lagged sea-ice influence}

119 The covariability between Atlantic SIC anomalies in a given month and monthly SLP

120 anomalies is examined for the same extended season as in Strong et al. (2009) and

121 Frankignoul et al. (2014), namely for SIC in December-to-April. Figure 1 summarizes

122 the MCA statistics for SC of the main mode of covariability upon the three different

123 SIC domains considered: the Atlantic basin of the Arctic Ocean (ATL; Fig. 1a) and its

124 sub-basins, east (eG; Fig. 1b) and west (wG; Fig. 1c) of Greenland. The MCA analysis

125 starts at lag zero, i.e. contemporaneous relationship, when the atmospheric forcing of

126 SIC fluctuations is expected to dominate (e.g. Deser et al. 2000; Frankignoul et al.

127 2014). Consistent with Figure 5 below, the first MCA mode at lag zero describes the 
128 SIC anomalies associated with the NAO forcing (not shown). Positive lags stand for

129 SIC changes leading SLP anomalies. At two-month lead-time, consistent with the

130 expected response time of the atmosphere to SIC anomalies (e.g. Deser et al. 2007),

131 there is a prominent SC peak between December SIC variability and the Euro-Atlantic

132 atmosphere in February, which is significant at 95\% confidence level and appears to be

133 dominated by SIC anomalies over eG (Figs. 1a-b, green); this lagged relationship is

134 analysed in Section 3.2. There is also a potential influence of January SIC variability

135 over $w G$ on the atmospheric circulation of February, which is significant at $90 \%$

136 confidence level (Fig. 1c, blue); this lagged relationship is discussed in Section 3.3. At

137 lead-times longer than the expected atmospheric response time to SIC forcing, there are

138 some indications of a potential influence of SIC variability over wG on the atmosphere

139 in April (Fig. 1c, blue) and July (Fig. 1c, yellow/magenta). As this study focuses on the

140 cold season, these signals are not discussed.

141

142 According to Fig. 1, the target months for the rest of the study are December/January

143 for SIC anomalies and January/February for atmospheric anomalies. The first step

144 towards understanding the potential influence of December/January SIC variability on

145 the Euro-Atlantic atmospheric circulation is to assess their persistence. Figure 2

146 illustrates the local persistence of (detrended) winter SIC anomalies over the Atlantic

147 basin by showing grid-point correlation maps between anomalies in December (left) and

148 January (right), and lagged anomalies. The largest correlations take place in the

149 marginal ice zones, around the climatological sea-ice edge (green contours). At two-

150 month lag, December SIC anomalies strongly persist in the Greenland and Barents Seas

151 and over the Davis Strait, whereas anomalies in the Labrador Sea vanish (Figs. 2a,b). At

152 one-month lag, January SIC anomalies yield a wider and stronger persistence area west 
153 of Greenland than December SIC anomalies (Figs. 2a,c), following the expansion of the

154 climatological edge and the increase in variability (Figs. 2d,e). These results are in 155 agreement with the long decaying time-scale of the winter NAO-driven SIC anomalies 156 shown by Strong et al. (2009), enabling the detection of its feedback onto the 157 atmosphere later in the season.

\subsection{Influence of December sea-ice on the atmosphere}

161 Figure 3 (left) shows the leading MCA mode between SIC anomalies over eG in

162 December and SLP anomalies over the North Atlantic-European region in February

163 (Fig. 1b, green; Table 1). The SIC pattern (Fig. 3a) resembles the well-known dipolar 164 signature induced by a positive NAO (see Fig. 5c below), with maximum sea-ice 165 reduction in the Greenland Sea $(\sim 30 \%)$. The SLP pattern (Fig. 3c) resembles the 166 negative phase of the NAO, which is the first EOF mode of SLP in February (Fig. 4a).

167 This MCA result points out the change in the NAO-like polarity between atmospheric 168 anomalies leading and lagging the December SIC anomalies east of Greenland.

170 To be independent of the MCA framework, an area-averaged SIC index is considered.

171 The area is $20^{\circ} \mathrm{W}-0^{\circ} \mathrm{E} / 68^{\circ} \mathrm{N}-80^{\circ} \mathrm{N}$, which is representative of the Greenland Sea 172 (hereafter SIC-GS ${ }_{\text {DEC }}$ ). The associated SIC pattern (Fig. 5a) is nearly identical to the 173 one in Fig. 3a, and the correlation between the respective time-series is 0.92 . This 174 pattern illustrates the strong coupling of SIC anomalies at both sides of Greenland due 175 to the NAO forcing (Fig. 5c). In the Greenland Sea, the increased heat release to the 176 atmosphere (Fig. 5e) results from the sea-ice reduction, which opens an ice-free ocean 
177 region. Elsewhere, the surface heat flux anomalies primarily reflect the imprint of the 178 positive NAO-like pattern (e.g. Cayan 1992).

179

180 In January, one month later, the SLP anomalies associated with SIC-GS DEC $_{\text {already }}$ 181 show hints of a negative NAO-like pattern, with positive anomalies at high latitudes and 182 negative ones at North Atlantic mid-latitudes, although they are weak and not

183 statistically significant (Fig. 6e). The most striking feature is the equivalent-barotropic

184 low over Europe, which has a westward tilt with height suggestive of Rossby wave 185 propagation (Fig. 6-left). The upper-tropospheric anomalies (Fig. 6c) share some 186 similarity with the transient response to prescribed sea-ice changes reported by Deser et 187 al. (2007). Likewise, the heat flux dipole-like anomaly over eG/wG, with 188 increased/reduced heat release (Fig. 7e), reflects the SIC damping found in other 189 AGCM studies (Alexander et al. 2004; Deser et al. 2004; Magnusdottir et al. 2004). The 190 surface heat flux anomalies over the Gulf Stream region also reflect a negative feedback 191 onto the NAO-related SST anomalies (cf. Figs. 5e with 7e). This suggests that the 192 circulation anomalies in January associated with SIC-GS $S_{\mathrm{DEC}}$ might be driven or 193 modulated by the sea-ice and associated SST changes (see discussion in Section 4).

195 In February, the negative NAO-like pattern associated with SIC-GS $\mathrm{DEC}_{\text {in }}$ is established 196 (Fig. 6f). This pattern consistently projects on the regional one from the MCA197 SIC/eG ${ }_{\text {DEC }}$ analysis (Fig. 3c). Interestingly, it is hemispheric in scale throughout the 198 troposphere and lower stratosphere (Fig. 6-right), but variations in the polar vortex are 199 barely statistically significant (Fig. 6b). The tropospheric anomalies (Figs. 6d,f) are in 200 agreement with the equilibrium response to prescribed sea-ice forcing in the Atlantic 201 basin from Deser et al. (2007). Composite analysis based on $+/-1$ std dev of the SIC- 
$202 \mathrm{GS}_{\mathrm{DEC}}$ index yields similar results (not shown). The imprint of the negative NAO-like

203 pattern dominates the surface heat flux anomalies associated with SIC-GS ${ }_{\mathrm{DEC}}$ (cf. Figs.

$2044 \mathrm{c}$ with $7 \mathrm{f}$ ), although some residual anomalous heat release remains east of Greenland.

205

206 Concerning the settling of the NAO-like pattern, from January to February, there is an

207 overall intensification of the eddy activity (Fig. 7, top-middle), suggesting that the 208 positive eddy feedback amplifies and establishes the large-scale atmospheric anomaly

209 (Deser et al. 2004, 2007). Consistent with the negative NAO-like pattern, SIC-GS DEC $_{\text {is }}$

210 associated with a reduction in eddy heat and momentum flux over the western North

211 Atlantic (Figs. 7b,d), indicating a weakening of the jet at its entrance. Over Europe,

212 SIC-GS $\mathrm{DEC}_{\text {is }}$ associated with an anomalous westerly-momentum deposition to the

213 south (Fig. 7b) and a southward displacement of low-level waves (Fig. 7d), representing

214 a weakening of the jet at its tail.

215

\subsection{Influence of January sea-ice on the atmosphere}

218 The lagged covariability between January SIC anomalies over wG and the Euro219 Atlantic atmospheric circulation in February (Fig. 1c, blue; Table 1) is displayed in Fig. 3-right. The SIC pattern (Fig. 3b) shows a widening of the signal over the Davis Strait-

221 Labrador Sea (DL) region as compared to the thin anomaly in December associated

222 with SIC variability over eG (Figs. 3a, 5a), which reflects the intra-seasonal increase in 223 extent and variance (Figs. 2d,e). The SLP pattern following sea-ice reduction over DL is 224 reminiscent of the East Atlantic (EA) pattern (Fig. 3d), which is the second EOF mode of SLP in February (Fig. 4b). There is thus an intra-seasonal change in the atmospheric 
226 circulation lagging SIC anomalies in December (NAO-like; Fig. 3c) and January (EA227 like; Fig. 3d).

229 To assess robustness of the MCA results, an are-averaged SIC index is computed over $23065^{\circ} \mathrm{W}-50^{\circ} \mathrm{W} / 52^{\circ} \mathrm{N}-68^{\circ} \mathrm{N}$, which covers most of the DL region (hereafter SIC-DLJAN). 231 The associated SIC pattern (Fig. 5b) rightly projects on the one in Fig. 3b, since their 232 corresponding time-series are highly correlated (0.99), and it is largely driven by the 233 NAO (Fig. 5d). As before, in addition to the strong NAO imprint in surface heat flux at 234 North Atlantic middle/subpolar latitudes (e.g. Cayan 1992), SIC-DL JAN is associated 235 with an increased heat release over the area where sea-ice has retreated (Fig. 5f).

237 In February, one month later, the anomalous heat release west of Greenland strongly remains (Fig. 8f). SIC-DLJAN recaptures the positive EA-like SLP pattern found with

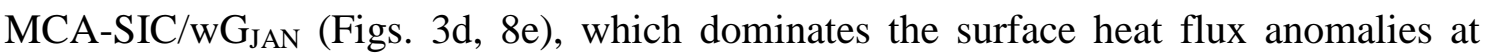

240 North Atlantic mid-latitudes (cf. Figs. 4d with 8f; see also Cayan 1992). The strong heat 241 release over the region of sea-ice reduction more clearly stands out when the latter 242 (obtained by linear regression of the EA principal component) is removed (Fig. 9a). The 243 related atmospheric warming in low levels (below 700hPa; Fig. 9b) should diminish the 244 meridional temperature gradient and local baroclinicity (e.g. Czaja et al. 2003); a 245 decrease in the eddy heat flux is indeed observed (Fig. 8d). SIC-DLJAN is also 246 associated with decreased westerly-momentum deposition towards the eddy-driven jet 247 (Fig. 8b). Together, eddy activity is consistent with the settling of the EA-like pattern 248 (e.g. Wettstein and Wallace 2010; Woollings et al. 2010). Note that the one-month 249 response time suggested by our analysis is in agreement with Ferreira and Frankignoul 250 (2005), who showed that the EA was responding more quickly to boundary forcing than 
the NAO. At the upper-troposphere (Fig. 8c), the EA-like Z200 pattern associated with SIC-DL JAN shows a dipolar structure confined to the North Atlantic basin, which is broadly consistent with the atmospheric response to SIC reduction over the Labrador Sea found by Kvamsto et al. (2004), with negative (positive) geopotential height anomalies at high (middle) latitudes, although their pattern resembled more a NAO-like structure. The regional scale of the anomalous circulation following SIC-DLJAN (Figs. $8 \mathrm{c}, \mathrm{e})$ is in qualitative agreement with the regional response to sea-ice changes west of Greenland reported by Magnusdottir et al. (2004), particularly as compared to the hemispheric response to sea-ice variations east of Greenland (their Fig. 3; see also discussion in Deser et al. 2004), but the sign is opposite in the respective patterns.

261 Composite analysis based on $+/-1$ std dev of the SIC-DLJAN index confirms that SIC anomalies are accompanied by an EA-like pattern at tropospheric levels (not shown). At the lower-stratosphere (Fig. 8a), the Z050 regression map of SIC-DL JAN shows a wave1 structure, however the link to stratospheric dynamics is unclear due to the asymmetry in statistical significance.

\section{Conclusions}

The relationship between observed monthly winter sea-ice anomalies in the Atlantic basin and lagged Euro-Atlantic atmospheric circulation has been investigated in the 1979-2013 period. The statistical approach followed in this study has led to some

272 interesting results that are summarized below:

274 - A statistically significant influence of the winter NAO-related SIC anomalies on the 275 atmospheric circulation has been found in two cases for the atmosphere in February, 
276 showing that this potential feedback can be detected in observations with monthly data,

277 which is consistent with their long decaying time-scale.

278

279 - There appears to be an intra-seasonal behaviour in this potential feedback: with SIC-

280 influence in December dominated by anomalies east of Greenland (maximum amplitude

281 in the Greenland Sea), and SIC-influence in January dominated by anomalies west of

282 Greenland. This feature may be linked to the larger expansion of the climatological sea-

283 ice edge and increase in variability in the Davis Strait-Labrador Sea region, from

284 December to January.

286 - The atmospheric anomalies lagging sea-ice changes in each sub-basin, at the target

287 month, are likewise different. The NAO-driven SIC anomalies in December are

288 followed in February by a NAO-like pattern of opposite polarity at the surface and a

289 hemispheric signature in the upper-troposphere/lower-stratosphere. But, the NAO-

290 driven SIC anomalies in January are then followed by a regional atmospheric anomaly

291 over the North Atlantic that projects on the EA pattern. Transient-eddy activity is likely

292 to be responsible for the settling of these atmospheric anomalies.

294 A caveat follows. The contribution of the NAO-induced SST anomalies to the Euro295 Atlantic atmospheric circulation accompanying sea-ice changes remains to be further 296 examined. Preliminary results, performing multiple-MCA (e.g. Polo et al. 2005) with

297 North Atlantic SST over $80^{\circ} \mathrm{W}-0^{\circ} \mathrm{E} / 0^{\circ} \mathrm{N}-70^{\circ} \mathrm{N}$ as additional predictor field (not shown), 298 suggest that SST anomalies could add to the influence of SIC anomalies east of 299 Greenland in December on the NAO-like atmospheric anomaly in February (sig.lev. for 300 SC 2\%), which is consistent with the discussion on surface heat flux in Section 3.2; but 
301 deteriorate the covariability between SIC anomalies west of Greenland in January and

302 the EA-like pattern in February (sig.lev. for SC 52\%), which might explain the weaker

303 statistical significance in the corresponding MCA-SIC analysis (Section 3.1).

304

305 We have described the influence of NAO-related December/January SIC anomalies

306 over the Atlantic basin on the North Atlantic-European circulation in February in terms

307 of potential feedback, as the direct boundary forcing is expected to be modest compared

308 to internal atmospheric variability. Hence, sensitivity AGCM experiments prescribing

309 sea-ice removal in each sub-basin would be useful to unambiguously identify the

310 mechanisms at work and the resulting atmospheric response; a coordinated multi-model

311 protocol would be desirable (Cohen et al. 2014; Gao et al. 2015). In addition, coupled

312 GCM experiments with an initial-value approach of the forcing, as in Wu et al. (2007),

313 would allow tracking the joint evolution of SIC/SST anomalies and associated

314 atmospheric response.

315

316 In this study, we have taken the convention to analyse atmospheric anomalies following

317 sea-ice reduction in the target Atlantic sub-basin. The results have pointed out that 318 negative SIC anomalies at both side of Greenland, in different months, are associated

319 with distinctive circulation anomalies in the Euro-Atlantic sector. This distinct SIC

320 influence could help interpreting AGCM responses to current or projected sea-ice

321 trends, related to sea-ice decline in both the Greenland-Barents Seas and the Davis

322 Strait-Labrador Sea region, which show conflicting results (e.g. Deser et al. 2010;

323 Screen et al. 2013, 2014). 


\section{Acknowledgments.}

The research leading to these results has received funding from the European Union 7th Framework Programme (FP7 2007-2013), under grant agreement n.308299 (NACLIM www.naclim.eu). JG-S was partially supported by the H2020-funded MSCA-IF-EF DPETNA project. The authors thank Francis Codron (LOCEAN-IPSL) for discussions and two anonymous reviewers for their comments on the manuscript.

\section{References}

Alexander MA, Bhatt US, Walsh JE, Timlin MS, Miller JS, Scott JD (2004) The atmospheric response to realistic Arctic sea ice anomalies in an AGCM during winter. $\mathrm{J}$ Clim 17:890-905.

Andrews DG, Holton JR, Leovy CB (1987) Middle atmospheric dynamics. Academic Press, London.

Bretherton SB, Smith C, Wallace JM (1992) An intercomparison of methods for finding coupled patterns in climate data. J Clim 5:541-560.

Cayan DR (1992) Latent and sensible heat flux anomalies over the Northern Oceans: the connection to monthly atmospheric circulation. J Clim 5:354-369.

Chang EKM, Fu Y (2002) Interdecadal variations in Northern Hemisphere winter storm track intensity. J Clim 15:642-658.

Cohen J, Screen JA, Furtado JC, Barlow M, Whittleston D, Coumou D, Francis J, Dethloff K, Entekhabi D, Overland J, Jones J (2014) Recent Arctic amplification and extreme mid-latitude weather. Nature Geosci 7:627-637.

Comiso JC (2000, updated 2012) Bootstrap sea ice concentrations from Nimbus-7 SMMR and DMSP SSM/I-SSMIS - version 2. Boulder, Colorado USA: NASA DAAC at the National Snow and Ice Data Center.

Czaja A, Frankignoul C (2002) Observed impact of Atlantic SST anomalies on the North Atlantic Oscillation. J Clim 15:606-623.

Czaja A, Robertson AW, Huck T (2003) The role of Atlantic ocean-atmosphere coupling in affecting the North Atlantic Oscillation variability. In: Hurrell JW, Kushnir Y, Ottersen G, Visbeck M (eds) The North Atlantic Oscillation: climatic significance and environmental impact. AGU Geophys Monogr Ser 134:147-172.

Dee DP et al (2011) The ERA-Interim reanalysis: configuration and performance of the data assimilation system. Q J R Meteorl Soc 137:553-597.

Deser C, Walsh JE, Timlin MS (2000) Arctic sea ice variability in the context of recent atmospheric circulation trends. J Clim 13:617-633. 
Deser C, Magnusdottir G, Saravanan R, Phillips A (2004) The effects of North Atlantic SST and sea ice anomalies on the winter circulation in CCM3. Part II: direct and indirect components of the response. J Clim 17:877-889.

Deser C, Tomas RA, Peng S (2007) The transient atmospheric circulation response to North Atlantic SST and sea ice anomalies. J Clim 20:4751-4767.

Deser C, Tomas R, Alexander MA, Lawrence D (2010) The seasonal atmospheric response to projected Arctic sea ice loss in the late twenty-first century. J Clim 23:333351.

Fang Z, Wallace JM (2009) Arctic sea ice variability on a timescale of weeks and its relation to atmospheric forcing. J Clim 7:1897-1914.

Ferreira D, Frankignoul C (2005) The transient atmospheric response to midlatitude SST anomalies. J. Clim 18:1049-1067.

Frankignoul C (1985) Sea surface temperature anomalies, planetary waves and air-sea feedback in the middle latitudes. Rev Geophys 23:357-390.

Frankignoul C, Czaja A, L'Heveder B (1998) Air-sea feedback in the North Atlantic and surface boundary conditions for ocean models. J Clim 11:2310-2324.

Frankignoul C, Sennéchael N, Cauchy P (2014) Observed atmospheric response to cold season sea ice variability in the Arctic. J Clim 27:1243-1254.

Gan B, Wu L (2015) Feedbacks of sea surface temperature to wintertime storm tracks in the North Atlantic. J Clim 28:306-323.

Gao Y, Sun J, Li F, He S, Sandven S, Yan Q, Zhang Z, Lohmann K, Keenlyside N, Furevik T, Suo L (2015) Arctic sea ice and Eurasian climate: a review. Adv Atmos Sci 32:92-114.

Hoskins BJ, James IN, White GH (1983) The shape, propagation and mean-flow interaction of large-scale weather systems. J Atmos Sci 40:1595-1612.

Hurrell JW, Kushnir Y, Ottersen G, Visbeck M (2003) An overview of the North Atlantic Oscillation. In: Hurrell JW, Kushnir Y, Ottersen G, Visbeck M (eds) The North Atlantic Oscillation: climatic significance and environmental impact. AGU Geophys Monogr Ser 134:1-36.

Hurrell JW, Deser C (2009) North Atlantic climate variability: the role of the North Atlantic Oscillation. J Mar Syst 78:28-41.

Kvamsto NG, Skeie P, Stephenson DB (2004) Impact of Labrador sea-ice extent on the North Atlantic Oscillation. Int J Climatol 24:603-612.

Magnusdottir G, Deser C, Saravanan R (2004) The effects of North Atlantic SST and sea ice anomalies on the winter circulation in CCM3. Part I: main features and storm track characteristics of the response. J Clim 17:857-876. 
Peng S, Robinson WA, Li S (2002) North Atlantic SST forcing of the NAO and relationships with intrinsic hemispheric variabilty. Geophys Res Lett 29:117/1-4.

Polo I, Rodríguez-Fonseca B, Sheinbaum J (2005) Northwest Africa upwelling and the Atlantic climate variability. Geophys Res Lett 32. doi:10.1029/2005GL023883.

Screen JA, Simmonds I, Deser C, Tomas R (2013) The atmospheric response to three decades of observed Arctic sea ice loss. J. Clim 26:1230-1248.

Screen JA, Deser C, Simmonds I, Tomas R (2014) Atmospheric impacts of Arctic seaice loss, 1979-2009: separating forced change from atmospheric internal variability. Clim Dyn 43:333-344.

Smith TM., Reynolds RW, Peterson TC, Lawrimore L (2008) Improvements to NOAA's historical merged land-ocean surface temperature analysis (1880-2006). J Clim 21:2283-2296.

Strong C, Magnusdottir G, Stern H (2009) Observed feedback between winter sea ice and the North Atlantic Oscillation. J Clim 22:6021-6032.

Trenberth KE (1986) An assessment of the impact of transient eddies on the zonal flow during a blocking episode using localized Eliassen-Palm flux diagnostics. J Atmos Sci 43:2070-2087.

Visbeck M, Chassignet EP, Curry RG, Delworth TL, Dickson RR, Krahmann G (2003) The ocean's response to North Atlantic Oscillation variability. In: Hurrell JW, Kushnir Y, Ottersen G, Visbeck M (eds) The North Atlantic Oscillation: climatic significance and environmental impact. AGU Geophys Monogr Ser 134:113-145.

Wallace JM, Lim GH, Blackmon ML (1988) Relationship between cyclone tracks, anticyclone tracks and baroclinic waveguides. J Atmos Sci 45:439-462.

Walsh JE, Johnson CM (1979) An analysis of Arctic sea ice fluctuations, 1953-1977. J Phys Oceanogr 9:580-591.

Wettstein JJ, Wallace JM (2010) Observed patterns of month-to-month storm-track variability and their relationship to the background flow. J Atmos Sci 67:1420-1437.

Woollings T, Hannachi A, Hoskins B (2010) Variability of the North Atlantic eddydriven jet stream. Q J R Meteorol Soc 136:856-868.

Wu L, He F, Liu Z, Li C (2007) Atmospheric teleconnections of tropical Atlantic variability: interhemispheric, tropical-extratropical, and cross-basin interactions. J Clim 20:856-870.

Wu Q, Zhang X (2010) Observed forcing-feedback process between Northern Hemisphere atmospheric circulation and Arctic sea ice coverage. J Geophys Res 115. doi:10.1029/2009JD013574. 


\begin{tabular}{|c|c|c|c|c|}
\hline & & SC & SCF & COR \\
\hline \multirow{3}{*}{$\begin{array}{c}\text { SIC }_{\text {DEC }} \\
\text { (lag 2) }\end{array}$} & ATL & $3.7(3 \%)$ & $64.7(12 \%)$ & $0.60(13 \%)$ \\
\hline & $e G$ & $3.2(3 \%)$ & $73.4(3 \%)$ & $0.59(23 \%)$ \\
\hline & wG & $0.7(46 \%)$ & $52.1(49 \%)$ & $0.39(51 \%)$ \\
\hline \multirow{3}{*}{$\begin{array}{c}\text { SIC JAN }_{\text {JAN }} \\
(\operatorname{lag} 1)\end{array}$} & ATL & $3.6(27 \%)$ & $49.8(38 \%)$ & $0.49(50 \%)$ \\
\hline & eG & $1.9(32 \%)$ & $52.9(44 \%)$ & $0.54(40 \%)$ \\
\hline & $w G$ & $2.5(9 \%)$ & $69.1(21 \%)$ & $0.52(9 \%)$ \\
\hline
\end{tabular}

Table 1. Summary of the statistics for the leading MCA mode between SIC anomalies in December (SIC $_{\mathrm{DEC}}$; top) / January (SIC $\mathrm{JAN}_{\mathrm{N}}$; bottom) and SLP anomalies over the North Atlantic-European region in February, providing two- and one-month lag respectively: squared covariance $\left(\mathrm{SC} ; \mathrm{x} 10^{8}\right.$ ), squared covariance fraction (SCF; \%), and correlation between expansion coefficients (COR); the estimated significance level is given in brackets. Different SIC domains are used: the Atlantic basin of the Arctic Ocean (ATL) and its sub-basins, east (eG) and west (wG) of Greenland. The targeted modes of the study, i.e. SIC/eG $\mathrm{DEC}_{\text {and }}$ SIC/wG $\mathrm{WAN}_{\mathrm{J}}$, are highlighted in italics. 
a) SC / Atlantic basin (ATL)

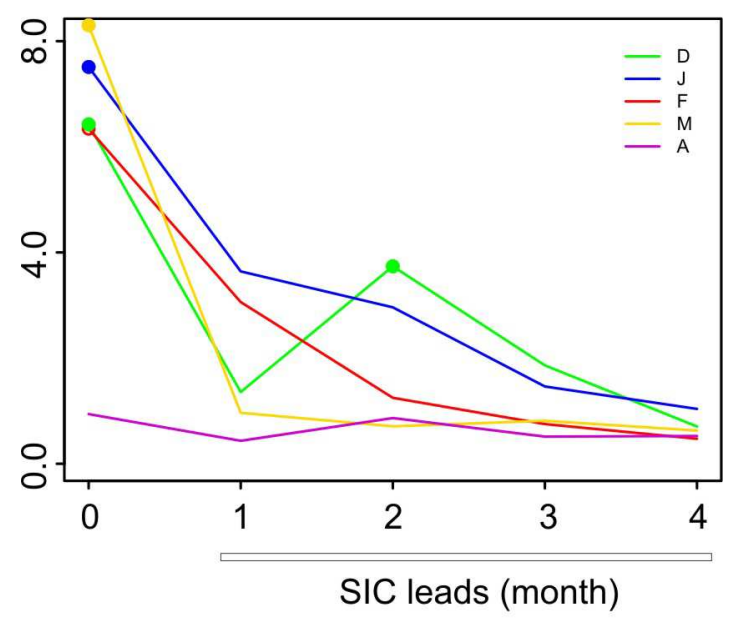

b) SC / east of Greenland (eG)

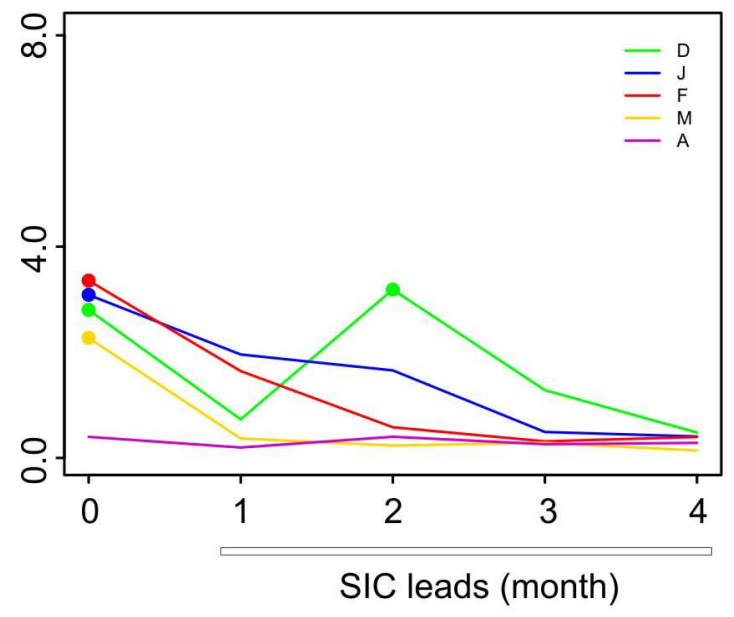

c) SC / west of Greenland (wG)

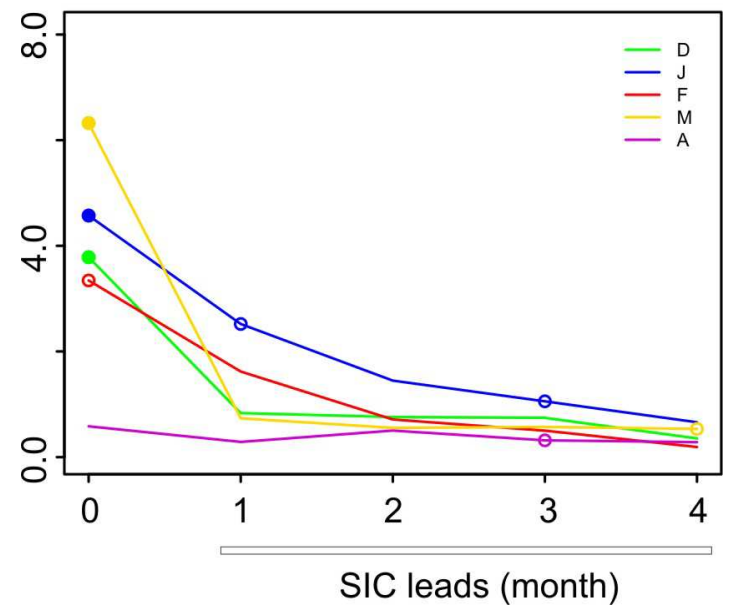

Figure 1. Squared covariance (SC; $\times 10^{8}$ ) of the first MCA mode between monthly detrended SIC anomalies (coloured lines) over the Atlantic basin (a), east (b) and west (c) of Greenland, and SLP anomalies over the North Atlantic-European region lagging by 0 to 4 months; solid (open) circle indicates statistically significant mode at 95\% (90\%) confidence level based on a Monte-Carlo test of 100 permutations shuffling only SLP with replacement. 

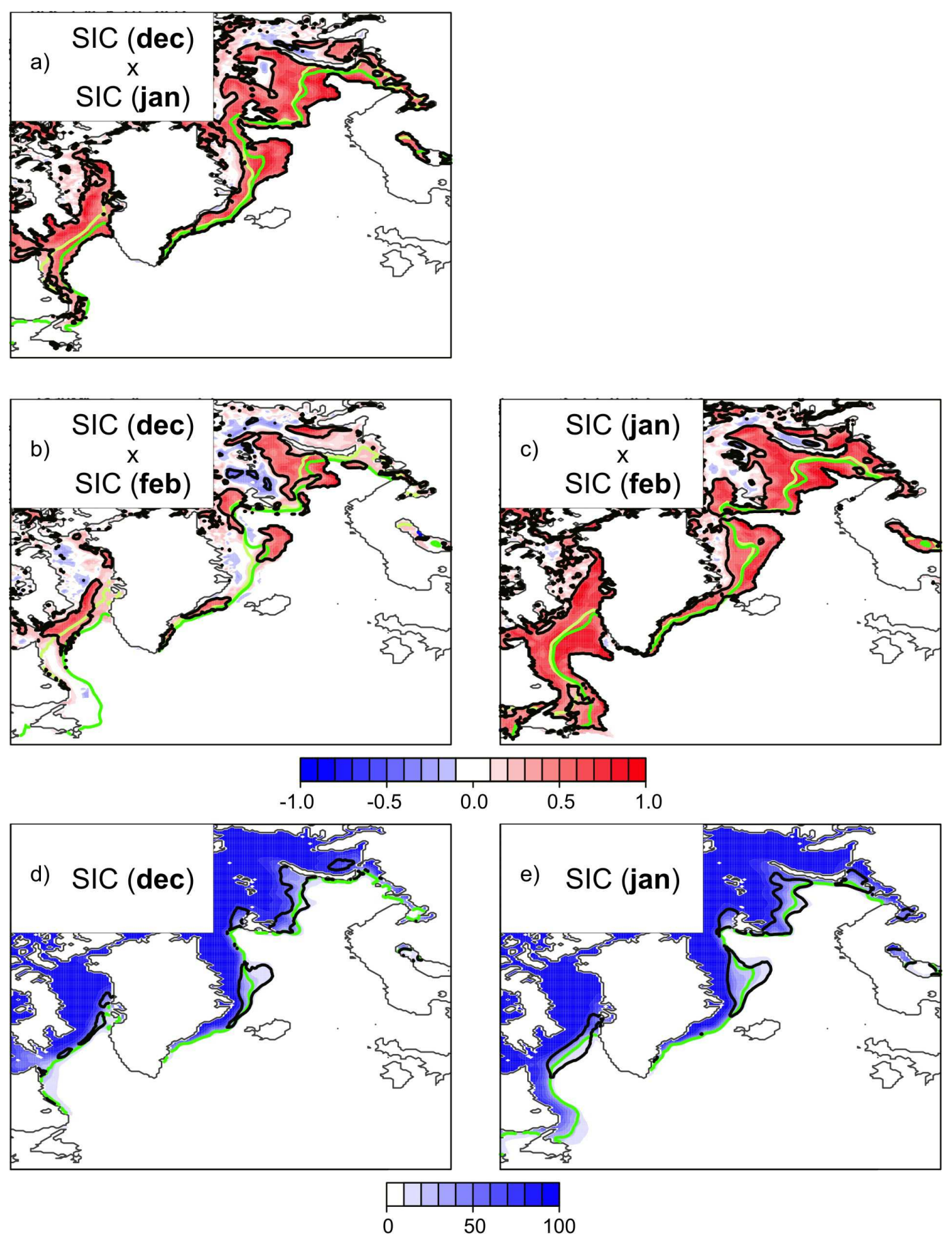

Figure 2. Grid-point correlation map of detrended SIC anomalies in December (a,b) and January (c) with anomalies one (a,c) or two (b) months later; light-green (green) contour stands for the climatological sea-ice edge in the target (lagged) month, estimated by the $25 \%$ fraction. Statistically significant areas at $95 \%$ confidence level based on a two-tailed $t$-test are contoured. [bottom] Climatology of SIC in December (d) and January (e) over the period 1979-2013; green contour stands for the climatological sea-ice edge estimated by the $25 \%$ fraction; black contour indicates the isoline of $25 \%$ for SIC standard deviation. 
a) MCA-SIC/eGdec $\times$ SIC (dec)

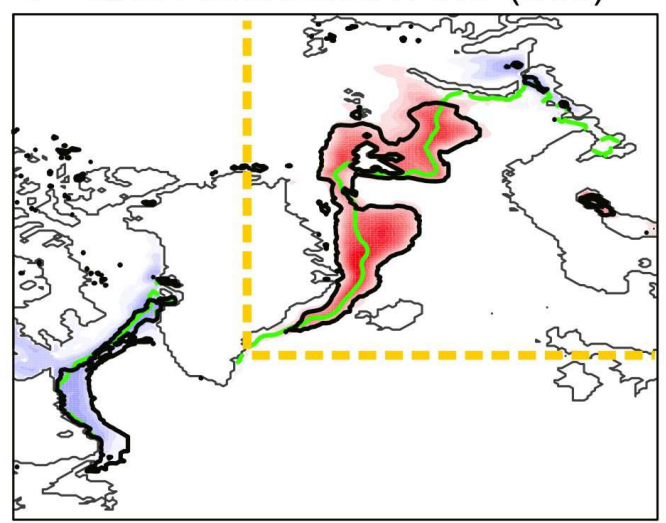

b) MCA-SIC/WGJAN $\times$ SIC (jan)

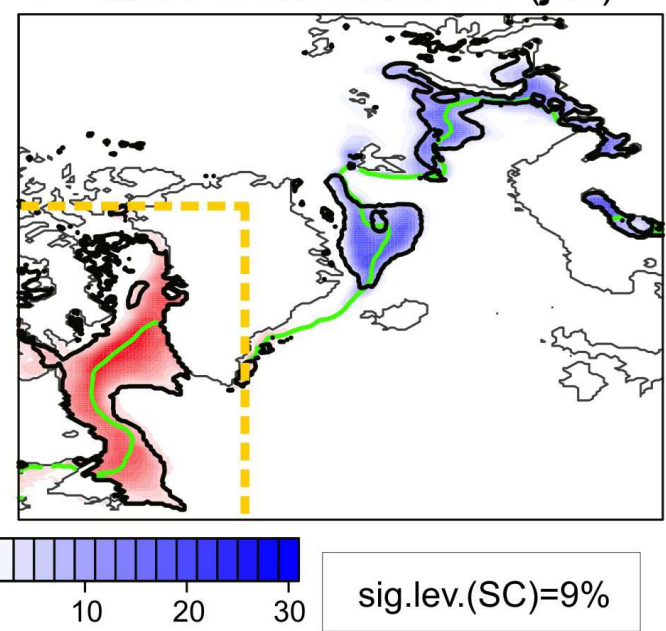

c) MCA-SIC/eGdec $\times$ SLP (feb)

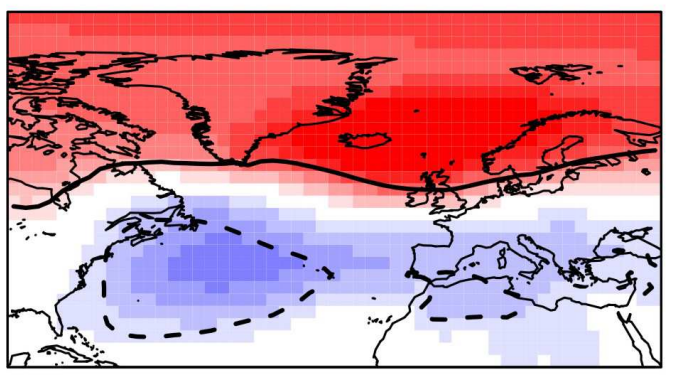

d) MCA-SIC/WGJAN $\times$ SLP (feb)

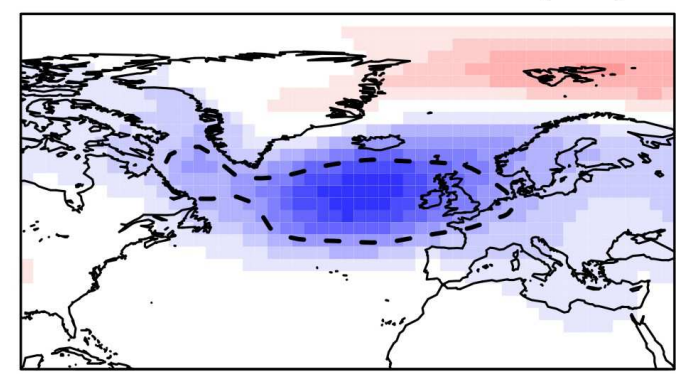

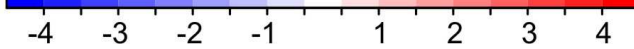

Figure 3. Leading MCA covariability mode between detrended SIC anomalies (\%; top) in December east of (eG; a) / January west of (wG; b) Greenland and SLP anomalies (hPa; bottom) in February, providing two- and one-month lag respectively; the estimated significance level for the SC of each mode (Fig. 1b,c) is indicated. Shown are regression maps of detrended anomalies onto the corresponding MCA-SIC expansion coefficient; amplitudes correspond to one std dev of the time-series. Green contour (in top) stands for the climatological seaice edge estimated by the $25 \%$ fraction; the yellow box indicates the SIC region used for the MCA analysis. Statistically significant areas at $95 \%$ confidence level based on a two-tailed $t$-test are contoured. 
a) NAO [EOF\#1 SLP, 42\%] (feb)

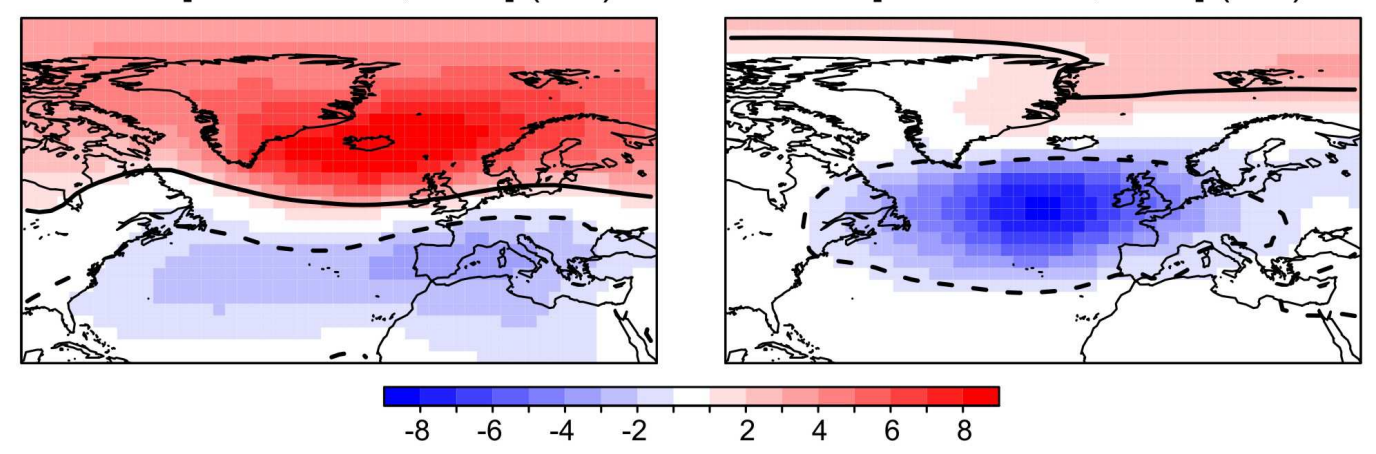

NAOFeb $\times$ shf+lhf (feb)

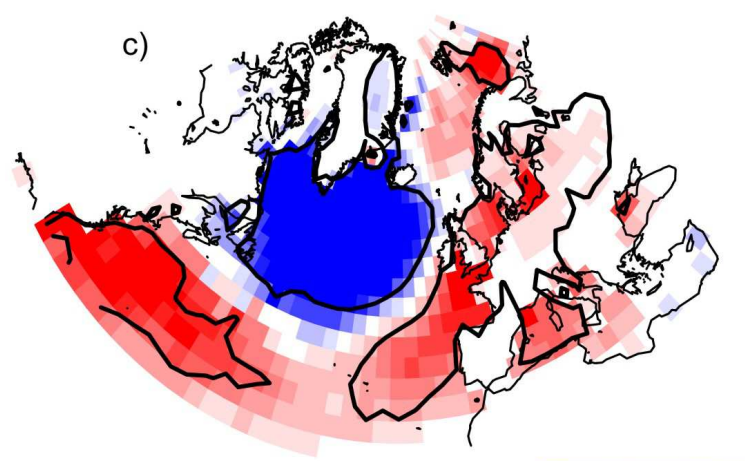

EAfeb $\times$ shf+lhf (feb)

d)

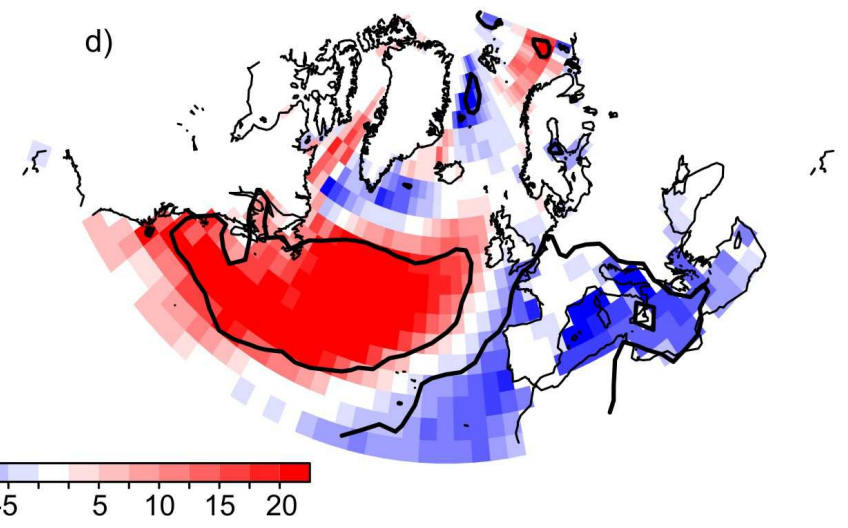

Figure 4. [top] First (a) and second (b) leading EOF modes of detrended SLP anomalies (hPa) in February over the North Atlantic-European region, corresponding to the NAO (negative phase is shown) and EA patterns respectively; the fraction of explained variance by each mode (\%) is indicated in the title. [bottom] Regression maps of detrended surface turbulent heat flux anomalies (sensible plus latent, $\mathrm{W} / \mathrm{m}^{2}$; upward is positive) onto the NAO (c) and EA (d) principal components in February. Shown are amplitudes associated with one std dev of the corresponding time-series. Statistically significant areas at $95 \%$ confidence level based on a two-tailed $t$-test are contoured. 
a) SIC-GS

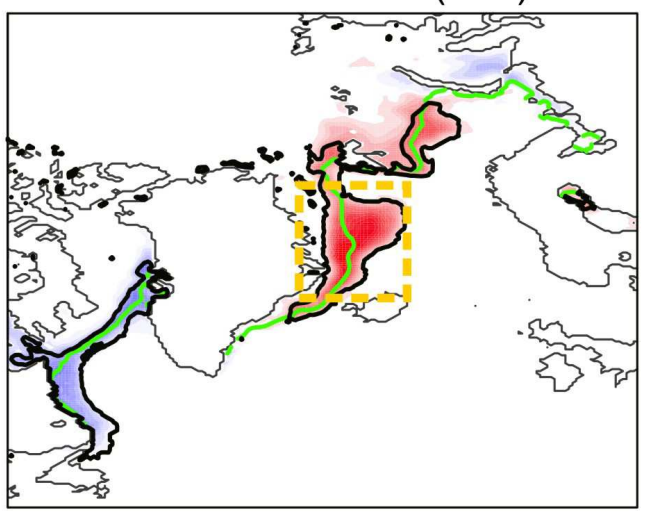

b) SIC-DLJAN X SIC (jan)

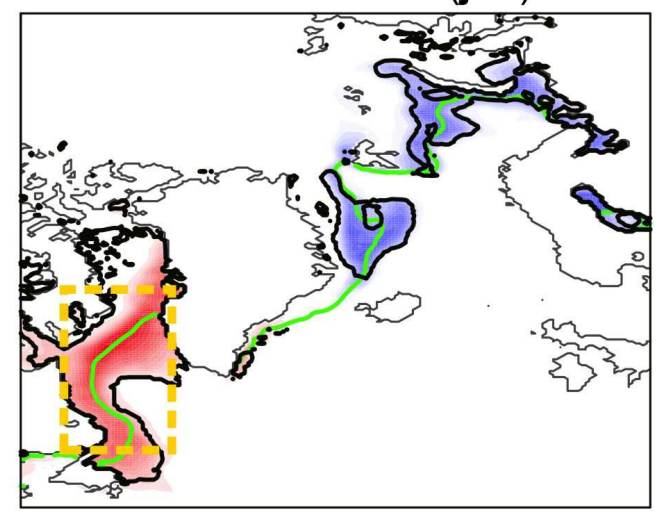

$10 \quad 20 \quad 30$

c) SIC-GS dec $\times$ SLP (dec)

d) SIC-DLJAN X SLP (jan)
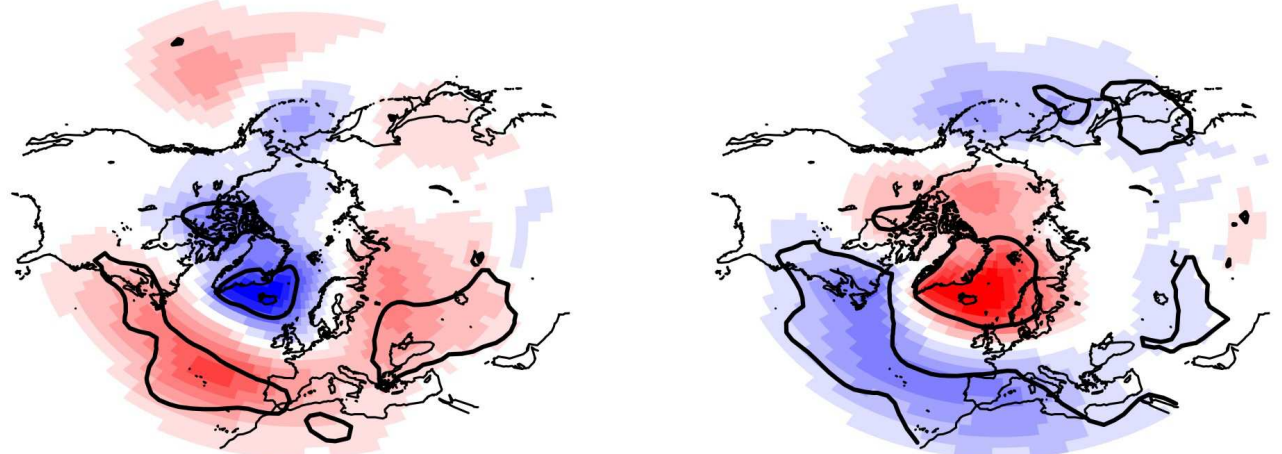

e) SIC-GS Dec $\times$ shf+lhf (dec)

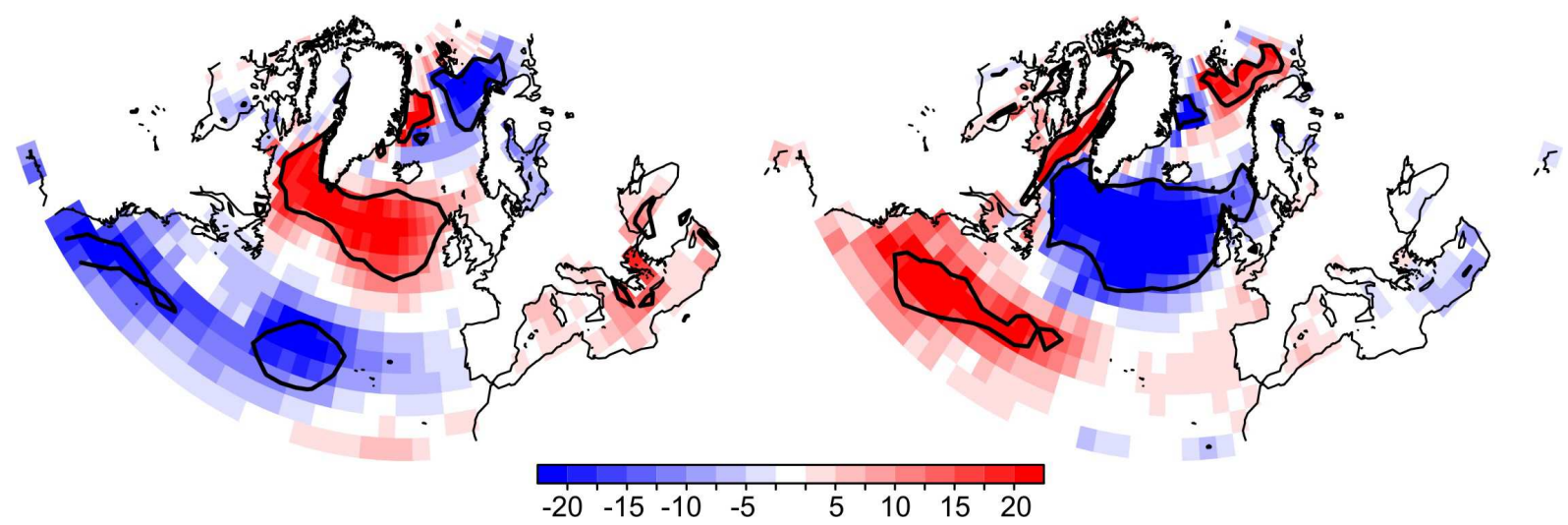

Figure 5. Regression maps of detrended SIC (\%; top), SLP (hPa; middle), and surface turbulent heat flux (sensible plus latent, $\mathrm{W} / \mathrm{m}^{2}$; upward is positive; bottom) anomalies in December onto the SIC-GS $\mathrm{DEC}_{\mathrm{DEC}}$ index (left), and in January onto the SIC-DL JAN $_{\mathrm{In}}$ index (right); amplitudes correspond to one std dev of the time-series. Green contour (in top) stands for the climatological sea-ice edge estimated by the $25 \%$ fraction; the yellow box indicates the region used to define the corresponding SIC index. Statistically significant areas at $95 \%$ confidence level based on a two-tailed $t$-test are contoured. 
a) SIC-GS dec X Z050 (jan)

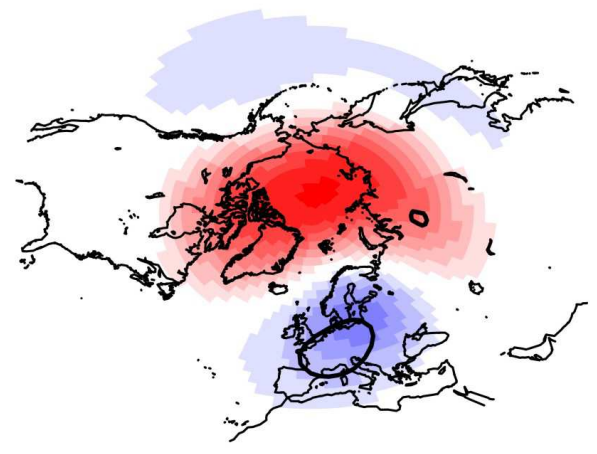

b) SIC-GS

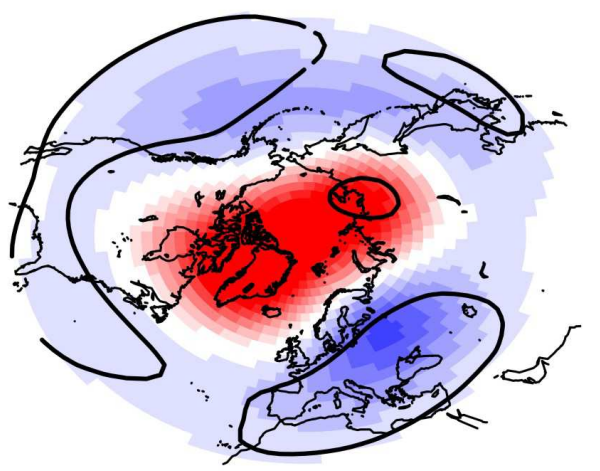

$\begin{array}{llllllll}-80 & -60 & -40 & -20 & 20 & 40 & 60 & 80\end{array}$

c) SIC-GS dec $\times$ Z200 (jan)

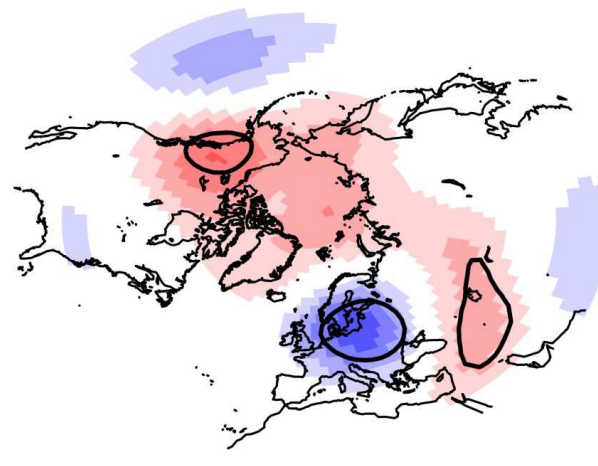

d) SIC-GS Dec $\times$ Z200 (feb)

e) SIC-GS

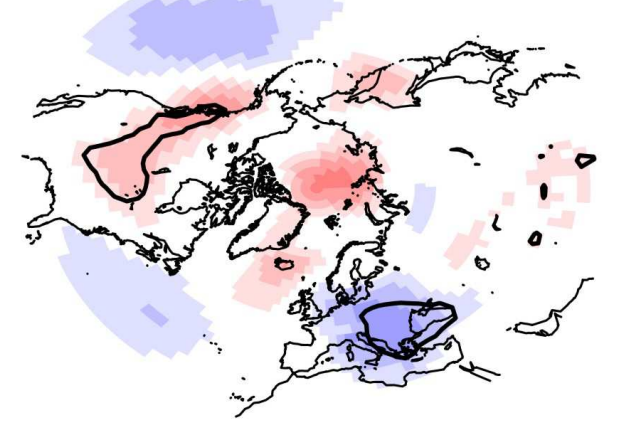

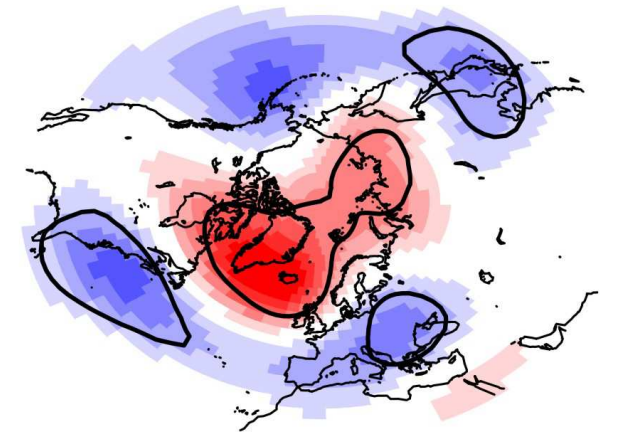

60

f) SIC-GS
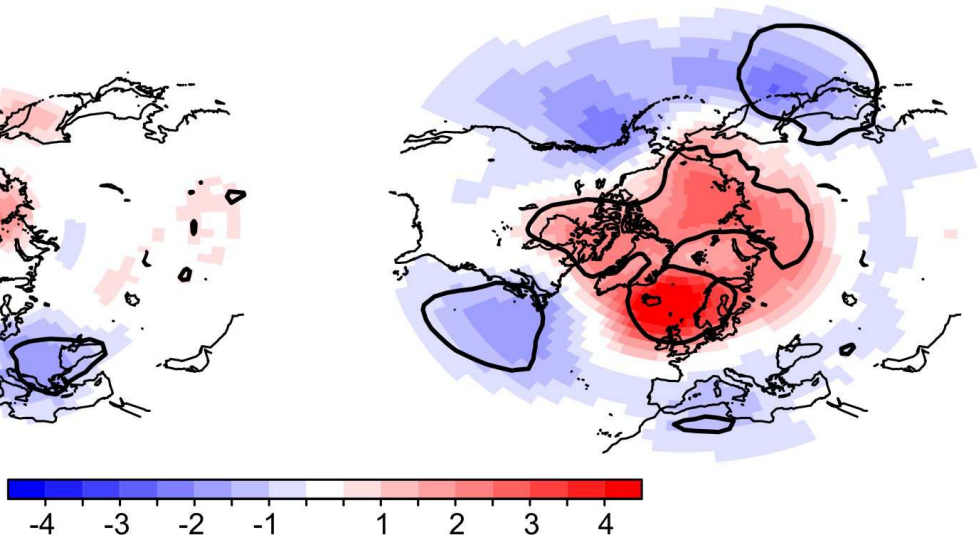

Figure 6. Regression maps of detrended geopotential height anomalies at $50 \mathrm{hPa}(\mathrm{Z050, \textrm {m }}$; top) and $200 \mathrm{hPa}$ (Z200, m; middle), and SLP anomalies (hPa; bottom) in January (left) and February (right) onto the SIC-GS index; amplitudes correspond to one std dev of the time-series. Statistically significant areas at $95 \%$ confidence level based on a two-tailed $t$-test are contoured. 
a) SIC-GS

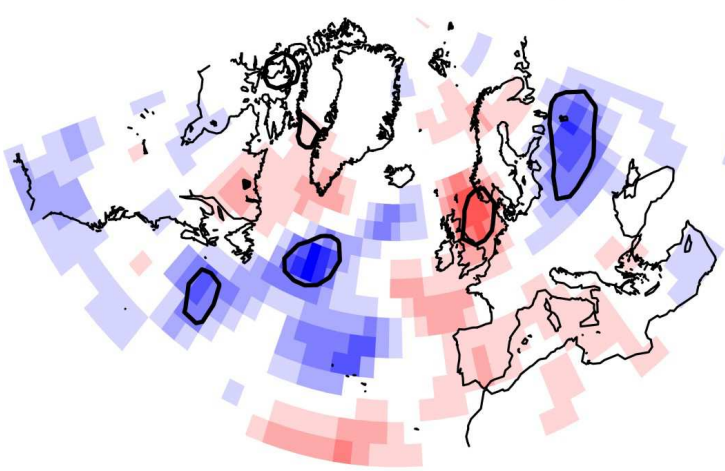

$\begin{array}{lll}-18 & -12 & -6\end{array}$ b) SIC-GS

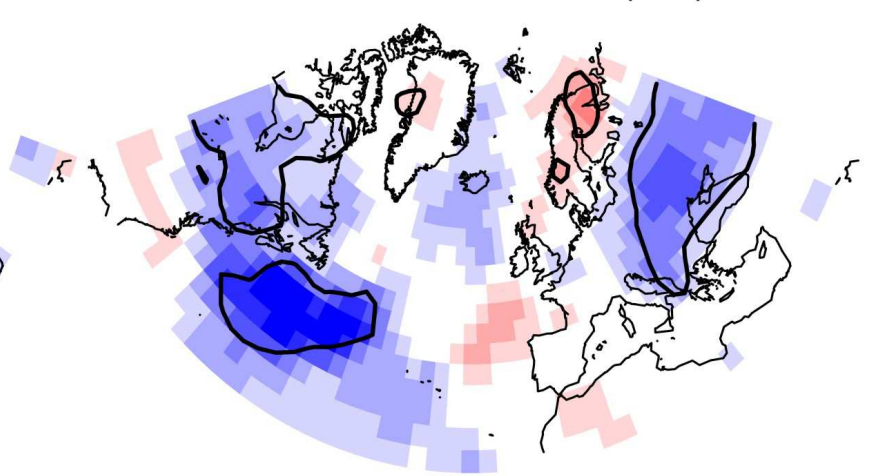

jan)

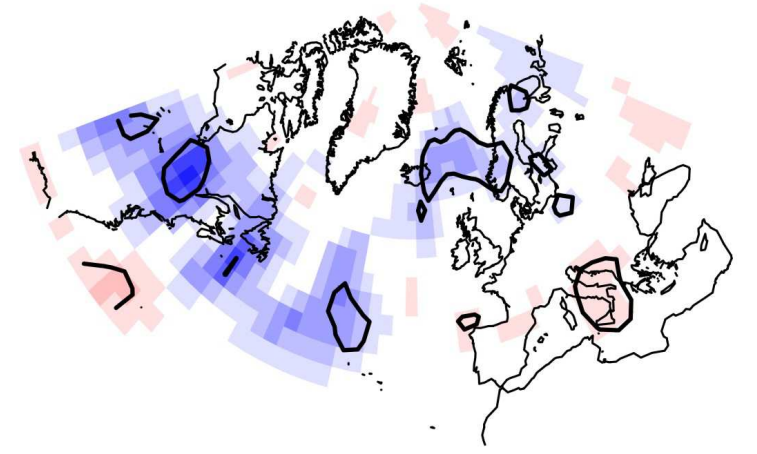
d) SIC-GS DEC $\times V^{\prime} T^{\prime} 850(\mathbf{f e b})$

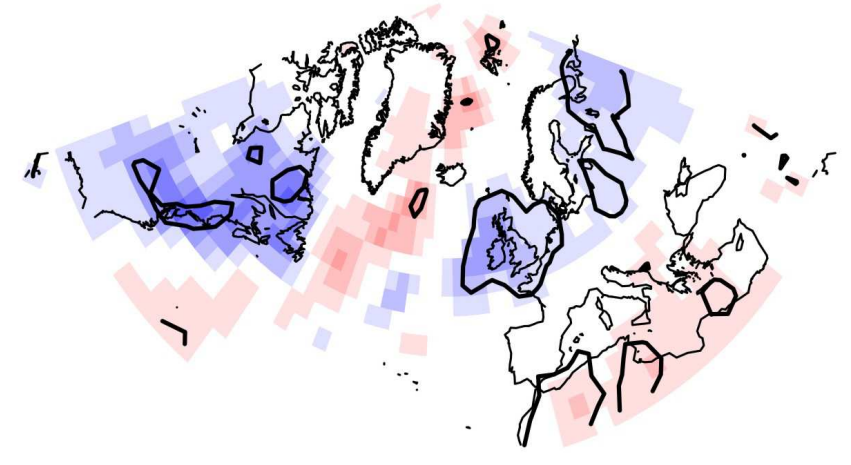

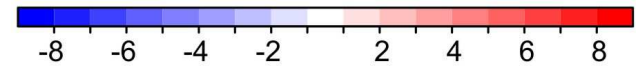

e) SIC-GS Dec $\times$ shf+lhf (jan)

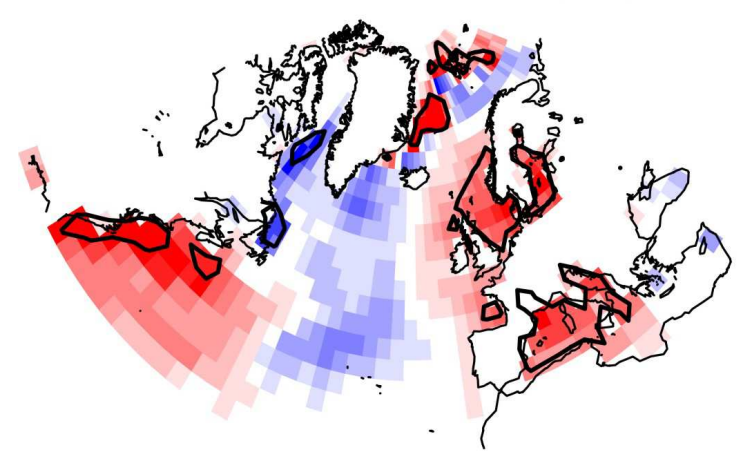

f) SIC-GS Dec $\times$ shf+lhf (feb)
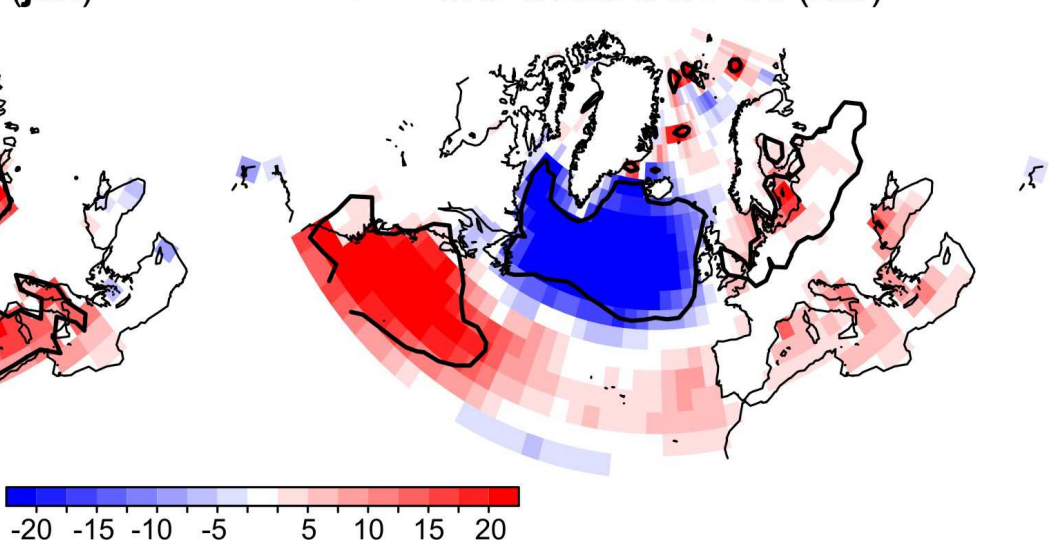

Figure 7. As Fig. 6, but of transient-eddy momentum flux at $200 \mathrm{hPa}\left(\mathrm{m}^{2} / \mathrm{s}^{2}\right.$; top), transient-eddy heat flux at $850 \mathrm{hPa}\left(\mathrm{mK} / \mathrm{s} ;\right.$ middle), and surface turbulent heat flux (sensible plus latent, $\mathrm{W} / \mathrm{m}^{2}$; upward is positive; bottom). 
a) SIC-DLJAN X Z050 (feb)

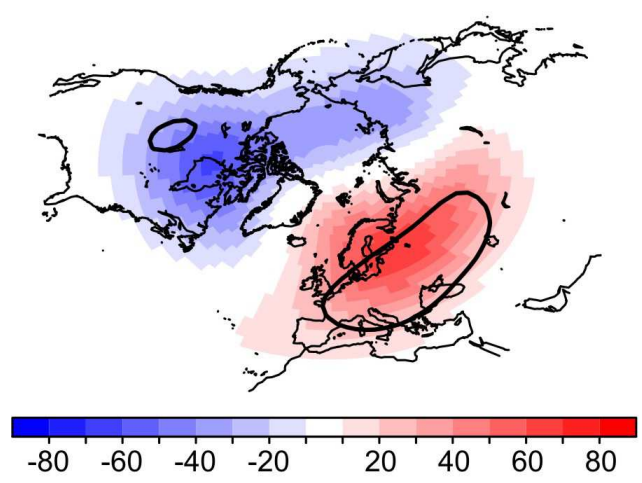

c) SIC-DLJan X Z200 (feb)

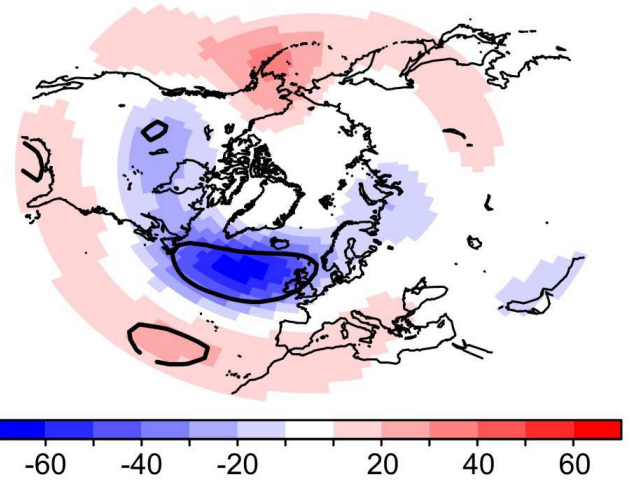

e) SIC-DLJan X SLP (feb)

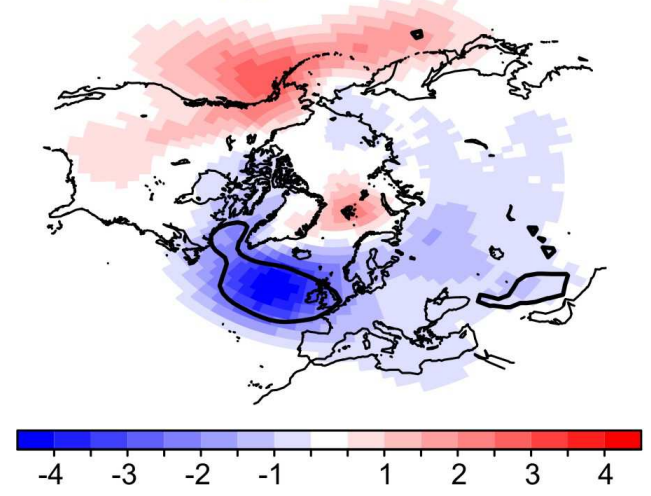

b) SIC-DLJan X U'v'200 (feb)

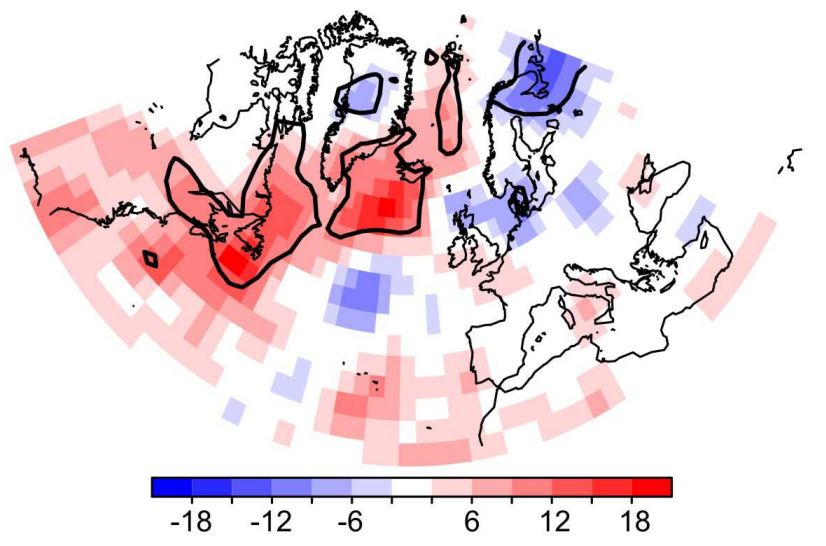

d) SIC-DLJan X v'T'850 (feb)

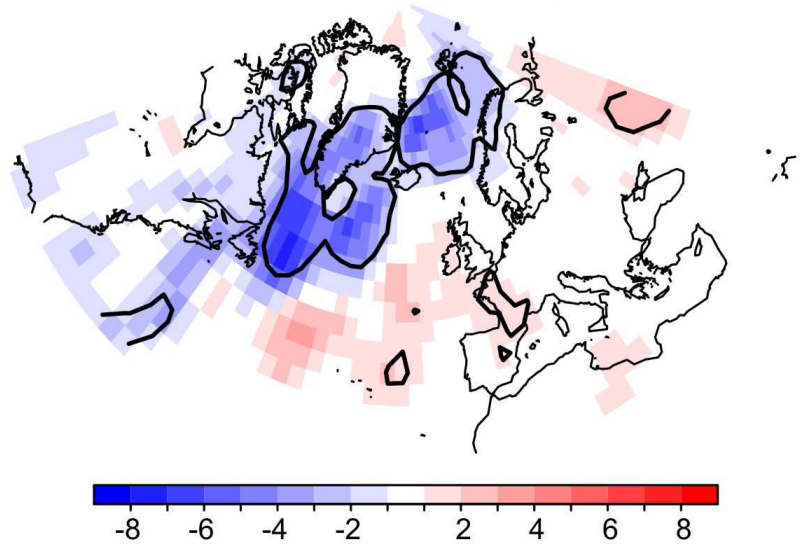

f) SIC-DLJan X shf+lhf (feb)

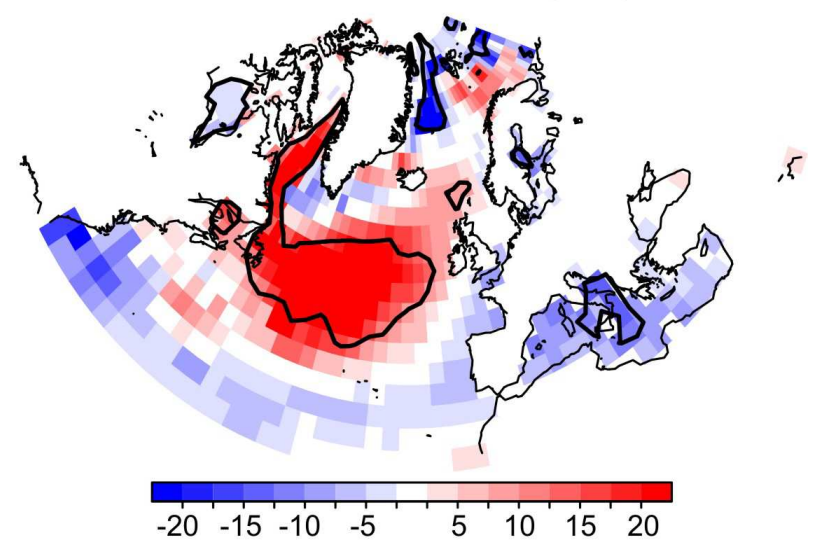

Figure 8. (left) As Fig. 8-right; (right) as Fig. 9-right, but onto the SIC-DL JAN $_{\text {index. }}$ 
SIC-DLJAN X shf+lhf/RESIDUAL (feb)

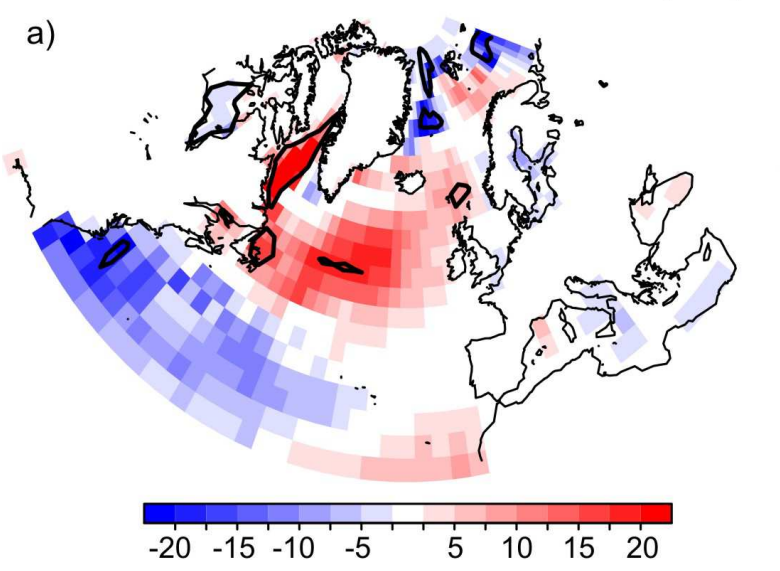

b) SIC-DLJan $x$ T[60W-45W] (feb)

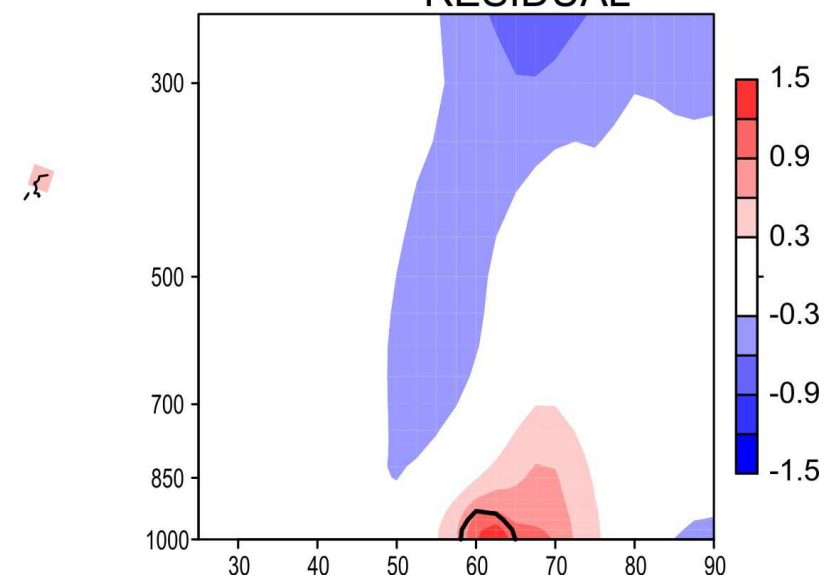

Figure 9. Regression of detrended surface turbulent heat flux anomalies (sensible plus latent, $\mathrm{W} / \mathrm{m}^{2}$; upward is positive; a) and air-temperature anomalies averaged over $60^{\circ} \mathrm{W}-45^{\circ} \mathrm{W}$ (pressure level $\mathrm{hPa}$ vs latitude ${ }^{\circ} \mathrm{N}, \mathrm{K}$; b) in

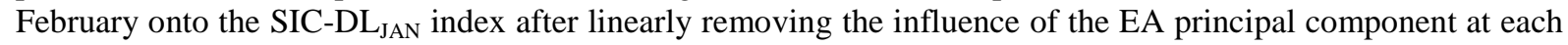
grid-point. Shown are amplitudes associated with one std dev of the time-series. Statistically significant areas at 95\% confidence level based on a two-tailed $t$-test are contoured. 